\title{
Correspondence
}

\section{Serum potassium change during the TURP syndrome by cell volume regulation}

\section{To the Editor:}

In the TURP syndrome, changes in serum potassium have not been evaluated precisely. Jensen ${ }^{1}$ described the causes of potassium change during the TURP syndrome, but others should be added.

If the serum potassium concentration does not change during the TURP syndrome it suggests that intracellular potassium is extruded to the extracellular space, to compensate for renal potassium losses and keep serum potassium constant.

Non-electrolyte hypotonic solutions, glycine, sorbitol or mannitol, are usually used as a perfusate for TURP, and the large leakage into the blood vessels makes the extracellular fluid hypotonic. Hypotonic stress in extracellular space induces cell swelling, but the swollen cells tend to return to their original volume within a few minutes. ${ }^{2,3}$ This physiological cell volume "regulatory volume decrease (RVD)," involves efflux of potassium and water from the intracellular space. ${ }^{4,5}$

Potassium extrusions from the cells by RVD have been reported in erythrocytes, lymphocytes, hepatocytes, and renal cells. ${ }^{2-4}$ Physiologically, these cells may be exposed to hypotonic stress by water drinking but they should keep their cell volume constant. In the TURP syndrome, these cells may also show an RVD response and extrude potassium into the extracellular space.

The RVD response should be considered in evaluating changes in serum potassium concentration during TURP syndrome.

\section{Munetaka Hirose MD \\ Yoshifumi Tanaka MD \\ Department of Anaesthesia \\ Kyoto Prefectural University of Medicine \\ Kamigyoku Kyoto 602 \\ Japan}

\section{REFERENCES}

1 Jensen V. The TURP syndrome. Can J Anaesth 1991; 38 : 90-7.

2 Haddad P, Graf J. Volume-regulatory $\mathrm{K}^{+}$fluxes in the isolated perfused rat liver: characterization by ion transport inhibitors. Am J Physiol 1989; 257: G357-63.

3 Joannidis $M$, Volkl $H$, Pfaller $W$, Lang $F$. Volume-regulatory potassium release from isolated perfused rat kidney. Renal Physiol Biochem 1989; 12: 338-46.

4 Eveloff $J L$, Warnock $D G$. Activation of ion transport systems during cell volume regulation. Am J Physiol 1987; 252 Fl-10.

5 Chamberlin $M E$, Strange $K$. Anisosmotic cell volume regulation: a comparative view. Am J Physiol 1989; 257: C159-73.

\section{REPLY}

Iappreciated the discussion concerning serum potassium change during TURP which was contributed by Dr. Hirose and Dr. Tanaka. Potassium is mostly an intracellular ion. When serum $\left[\mathrm{K}^{+}\right]$is diluted by irrigating fluid, then intracellular potassium is extruded to the extracellular space in compensation. As well explained by Dr. Hirose and Dr. Tanaka, the regulatory volume decrease (RVD) response would help to explain this potassium flux, so there would be no serum $\left(K^{+}\right)$change during relatively small absorptions. The distribution of potassium in the body is regulated by a myriad of factors. The normal high intracellular to extracellular potassium concentration is dependent on the Na-K-ATPase pump. Other influences on the distribution of potassium between the intracellular and extracellular fluid compartments are three hormones (insulin, epinephrine, and aldosterone), acid-base status, and plasma tonicity.' The effect of tonicity is opposite to that of the RVD response.

Serum potassium change during TURP with glycine, 1.5\%, depends on the rate and amount of irrigating fluid absorption. If $300 \mathrm{ml}$ of irrigating fluid is absorbed during the case, then there is no change in serum $\left[\mathrm{K}^{+}\right] .^{2}$ If a patient absorbs $>300 \mathrm{ml}$ of irrigating fluid intravascularly, then serum $\left[K^{+}\right]$is increased by $0.5 \mathrm{mmol} \cdot L^{-1}$ by the end of the case. ${ }^{3}$ An increased serum $\left[K^{+}\right]$ at the end of the surgery is a sign of irrigating fluid absorption, ${ }^{3}$ subsequently, a decrease in serum [ $\left[\mathrm{K}^{+}\right]$occurs 6 to $48 \mathrm{hr}$ after the surgery. ${ }^{4}$

After glycine is absorbed, it moves intracellularly where it is metabolized. The system for glycine transport across the cell membrane is connected to the Na-K-ATPase pump. ${ }^{4}$ Norlen states that a high plasma concentration of glycine may interfere with the transmembrane electrolyte exchange, leading to a rise in serum $\left[K^{+}\right] .{ }^{4}$ The decrease in serum $\left[K^{+}\right]$which occurs six hours after surgery may indicate a shift of potassium intracellularly, after the glycine has been metabolized. Transient acidosis, leakage from injured prostatic cells, the RVD response and haemolysis might also increase the serum $\left[\mathrm{K}^{+}\right]$at the end of the TURP.

\section{Jensen MD FRCPC}

Edmonton 